\title{
Infections in Transplanted Patients
}

\author{
Margarita Gospodinova ${ }^{1}$, Iliyan Todorov ${ }^{1}$ and Ilko Bakardzhiev ${ }^{2 *}$ \\ ${ }^{1}$ Department of Infectious Diseases, Medical University of Varna, Bulgaria \\ ${ }^{2}$ Medical College, Medical University of Varna, Bulgaria
}

Received: December 21, 2017; Accepted: December 29, 2017; Published: January 05, 2018

*Corresponding author: Ilko Bakardzhiev, Associate Professor, Medical College, Medical University of Varna, Tsar Osvoboditel 84, Bulgaria, Tel: +359888 768413; E-mail: varna2008@gmail.com

\section{Abstract}

Solid-organ transplantation is a therapeutic option for many end-stage diseases. One of the most common complications in the post-transplant period are different kind of infections. They are caused by some bacterial pathogens such as Legionella spp., Nocardia spp., Salmonella spp. and Listeria monocytogenes, many viral agents - Cytomegalovirus /CMV/, Herpes simplex virus / HSV/, Varicella-zoster virus /VZV/, Epstein-Barr virus /EBV/, and more rarely - fungi and parasites. The onset of the signs and symptoms is essential for establishing the diagnosis - wound infections occur during the first 30 days after transplantation, opportunistic infections - 2 to 6 month later, and beyond 6 months, recipients suffer from the same infections distributed in the general community. Infections in solid-organ transplant recipients are global socio-medical problem, leading to prolonged hospital stay, significant financial losses and disability /and high mortality rate/ of the patients.

\section{Keywords}

Infections; Transplantation; Bacteria; Virus; Fungi; Recipient, Donor; CMV;

Solid-organ transplantation is a therapeutic option for many end-stage diseases. According to World Health Organization / WHO/, 115.000 organ transplantations are performed worldwide annually $-70 \%$ of kidneys, $20 \%$ of liver and $10 \%$ of heart, lungs and pancreas $[15,21]$. The term 'donor' is used about the patients who donate their organs to the 'recipient' - an individual who receive the donor's organ.

The early period after transplantation is essential for the success of the operation. At this time, severe immunosuppression is induced and recipients are threatened by infections with different microorganisms, which are distributed in the environment [16]. This interaction /microorganisms + macroorganisms + environment/ results in development of different infectious diseases, which take their clinical course in organism with impaired host defense. In such circumstances common infections may lead to severe and generalized clinical forms that are behind the rejection of the transplanted organ and high mortality rate in the recipient.

The risk factors for infectious diseases development in transplanted patients are shown in a table 1. Impaired mechanical barriers or stasis of secretions/excretions in the region of transplanted organ mainly are one of the most common risk factors leading to direct microbial invasion or bacterial overgrowth and subsequent inflammation. So a direct relationship between transplanted organ and the region of presented inflammatory process exists - infections of kidney and urinary tract in kidneys transplanted patients, infections of respiratory system after lungs transplantations etc [6].

Table 1: Host Defense Abnormalities and Their Causes, Infections in Transplant Recipients: An Overview - Medscape - Jul 31, 2015.

\begin{tabular}{|c|c|}
\hline Host Defense & Examples of Impairment \\
\hline $\begin{array}{c}\text { Anatomical barriers to } \\
\text { infection }\end{array}$ & $\begin{array}{c}\text { Surgical wound, implanted devices, } \\
\text { anastomosis problems, ischemia }\end{array}$ \\
\hline $\begin{array}{c}\text { Abnormal flow of body } \\
\text { fluids (urine, bile, } \\
\text { respiratory secretion) }\end{array}$ & $\begin{array}{c}\text { Post-transplant ureteral, biliary or } \\
\text { bronchial obstruction, urinary reflux, } \\
\text { neurogenic bladder, aspiration }\end{array}$ \\
\hline $\begin{array}{c}\text { Innate immunity } \\
\text { (neutrophils, } \\
\text { macrophages, } \\
\text { monocytes) }\end{array}$ & $\begin{array}{c}\text { Corticosteroids; medication-induced } \\
\text { myelosuppression }\end{array}$ \\
\hline $\begin{array}{c}\text { Adaptive immunity (T } \\
\text { cells and B cells) }\end{array}$ & $\begin{array}{c}\text { Corticosteroids, calcineurin inhibitors, } \\
\text { mycophenolate, rituximab, belatacept }\end{array}$ \\
\hline Complement function & Eculizumab \\
\hline Splenic function & Transplant-associated splenectomy \\
\hline
\end{tabular}

Patients underlying conditions also have a potential to damage organ systems. Neurogenic bladder in patient with diabetes mellitus or vesicoureteral reflux in children with congenital anomalies of kidney and the urinary tract are one of the most prevalent, while the bile duct strictures in the course of sclerosing cholangitis or bronchial obstruction during cystic fibrosis are rarely seen [7].

Immunosuppressive treatment, used in the post-transplant period, is associated with immune tolerance establishing which prevents organ rejection, but on the other side, it results in increased risk for infections. Commonly used regimen is a combination among steroids, calcineurin inhibitors - tacrolimus, cyclosporine and mycophenolate/azathioprine causing severe 
leukocytopenia, particularly lymphocytopenia. Significant neutropenia is associated with the use of also mycophenolate, together with trimetoprim-sulfametoxazol /TMP-SMX/ and valgancyclovir. Monoclonal antibodies affect the cellular and humoral immune response. For example, 'rituximab' destroys B-cells and decreases the immunoglobulin production, and 'eculizumab', which is anti-thymocyte globulin leads to quantitative changes in the complement system [20].

Twogroups of infections in transplanted patients-endogenous and exogenous are known, on the base of the route by which microorganisms enter into the human's body. Endogenous one appears as a result of activated viruses /which stay latent in the human's body after primary infections/ or bacterial overgrowth in non-sterile anatomic regions /gastrointestinal tract, skin, etc./. Therefore, it is not surprising that commonly isolated agent, responsible for inflammation after transplantation are normal flora for the relevant anatomic region [7,8]. For example, lungs infections in transplanted patients are caused by Pseudomonas aeruginosa, Aspergillus spp., Pneumocystis jiroveci; infections after kidneys, liver and pancreas transplantations are caused by Enterococcus, Escherichia coli, Bacteroides spp., Clostridium spp. It is important to know that skin microbiome and many viruses - cytomegalovirus /CMV/, herpes-simplex virus /HSV/, varicellazoster virus /VZV/, Epstein-Barr virus /EBV/, human herpesvirus $6 / \mathrm{HHV}-6 /$, hepatitis B virus /HBV/, hepatitis C virus /HCV/, BK virus, John Cunningham virus /JC virus/, do not cause infections in specific part of the body but may appear in all transplanted patients $[1,5,11,12,18]$.

Exogenous infections result from environment or they are donor-derived. Respiratory viruses such as influenza, parainfluenza, respiratory syncytial virus /RSV/, adenoviruses, rhinoviruses, human metapneumoviruses /hMPV/ as well as fungi and Nocardia may infect all transplanted patients, but most common lung transplanted. Fecal - oral mode of transmission, which is typical for Salmonella spp., Listeria spp., Cryptosporidium, Microsporidium lead to gastrointestinal tract infections, bacteremia or infections of the central nervous system, observed in all transplanted patients without underlying dependence on transplanted organ [3,5,11].

Donor-derived infections /DDI/ are special group of diseases, which also may be seen in all transplanted patients. They are caused by agents, which had been infected donor's body before transplantation and which transmission is expected to be in the recipient /it is known that donor is infected/. The etiological spectrum is wide, but $C M V, E B V, H B V$, Toxoplasma gondii are the most important one. The DDI may be unexpected, caused by human immunodeficiency virus /HIV/, hepatitis C virus / HCV/, lymphocytic choriomeningitis virus, Mycobacterium tuberculosis, rabies, West Nile virus $/ W N V /[9,10]$.

Most cases of infections in transplanted patients are caused by different bacteria strains. After liver transplantations, bacteria are responsible for $33 \%$ to $68 \%$ of all infections observed in recipients, in heart transplanted - $21-30 \%$ of cases, $35 \%$ in pancreas transplantations, $47 \%$ and $54 \%$ of infections in kidney and lungs transplantations respectively. The risk for bacterial infections depends on: the technical implementation of the transplantation, the duration of the hospital stay, immunosuppressive drugs regimen. It is known that bacterialcaused infections are presented in specific period after transplantation, which correlates with the appropriate diagnosis /see table $2 /[1,21]$.

\begin{tabular}{|c|c|c|c|}
\hline $\begin{array}{c}\text { Type of } \\
\text { Transplantation }\end{array}$ & Causative Agents & Symptoms Onset & Clinical Presentation \\
\hline Liver & $\begin{array}{l}\text { Enterococcus spp, } \mathrm{VRE}^{*} \text {, anaerobes, } \\
\text { Enterobacteriaceae }\end{array}$ & 2 months after transplantation & Hepatitis, liver abscesses, peritonitis \\
\hline Lungs & $\begin{array}{l}\text { Klebsiella pneumoniae, Pseudomonas } \\
\text { aeruginosa, Escherichia coli, } \\
\text { Staphylococcus aureus, Enterobacter } \\
\text { cloacae }\end{array}$ & 2 weeks after transplantation & Pneumonia, bronchitis, lung abscesses \\
\hline Kidneys & $\begin{array}{l}\text { Enterococcus, Staphylococcus, } \\
\text { Pseudomonas aeruginosa, Gram } \\
\text { negative enteric bacteria }\end{array}$ & $\begin{array}{l}\text { After discharging from the } \\
\text { hospital }\end{array}$ & $\begin{array}{l}\text { Infections of the operative wound /the } \\
\text { risk correlates with high serum creatinine } \\
\text { concentration/, urinary tract infections / the } \\
\text { risk correlates with prolonged hemodialysis } \\
\text { before operation/ }\end{array}$ \\
\hline Pancreas & $\begin{array}{l}\text { Enterococcus, Staphylococcus, } \\
\text { Pseudomonas aeruginosa, Gram } \\
\text { negative enteric bacteria }\end{array}$ & $\begin{array}{l}\text { After discharging from the } \\
\text { hospital }\end{array}$ & $\begin{array}{l}\text { Infections of the operative wound, } \\
\text { intraperitoneal abscesses, pelvic abscesses, } \\
\text { peritonitis, perirectal abscesses }\end{array}$ \\
\hline
\end{tabular}


Bacterial agents mentioned below, are one of the most frequently isolated strains as a causative agents of infections in transplanted patients:

- Legionella spp. - two kind of legionella infection exist: nosocomial and community acquired. Respiratory mode of transmission is realized by inhaling aerosole particles produced by air-conditioners, aerosol filling machine, showers, physiotherapy departments where water procedures are implemented, etc. The kind of infection is not associated with the severity of disease. The first clinical signs and symptoms are presented weeks after transplantation, together with graft rejection manifestation. Consequently, a Legionella infection in transplanted patients is a specific marker for forthcoming/presented graft rejection. One of the most important serotypes is Legionella pneumophila, L. micdadei, L. bozemanii and L. dumoffii. Clinical course of the disease includes severe pneumonia occurrence, and more rarely some extra-pulmonary manifestations such as hepatitis and peritonitis or pericarditis, which are typically seen in kidneys and heart transplanted patients, respectively $[7,8]$.

- Salmonella spp. - because of their clinical polymorphism, salmonella infections after transplantations are associated with many diagnostic and differential diagnostic difficulties. The risk for infection is strongly associated with antirejection therapy. The most common symptom is fever and blood cultures are positive in $99 \%$ [2]. Except of bacteremia, different organ involvements are possible: pyelonephritis, orchitis, perinephric abscesses, lung infections /pneumonia, lung abscess, pleural effusion/, vascular infections /infections of saccular aneurysms, arteriovenous fistula/, sinusitis, meningitis, cholecystitis etc.

- Listeria monocytogenes - is a specific causative agent of infections in transplanted patients. The risk period for infection is about 2 months after transplantation. Seasonal variations are typical - high frequency after transplantations during summer and autumn. In $2 / 3$ of the infected persons, central nervous system alone is involved - meningitis, meningoencephalitis, encephalitis. In the rest $1 / 3$ of the patients, just bacteremia with/ without secondary infections of lungs, eyes, heart, and rectum is seen $[1,7,8]$.

- Other bacterial infections - Mycoplasma hominis has been reported in liver transplant recipients, Ureaplasma urealyticum causes mediastinitis following heart-lung transplantations, and Rhodococcus equi - pulmonary infections after heart transplantations $[8,13]$.

With regards to viral agents which cause infections in transplanted patients, microbial spectrum is wider together with significant variations in clinical presentation /in some cases just as a fever of unknown origin/ leading to many difficulties in establishing the right diagnosis such as late diagnosed and misdiagnosed patients. It is behind the high mortality rate - a basic feature of this group of infections.

- $\boldsymbol{C M V}$ - is highly associated with severe immunosuppression and is typically seen in the first 3 months after transplantation. CMV infection occurs in 44 to $85 \%$ of kidney, heart, and liver transplant recipients [15]. The infection is donor derived / after transplantation of previously infected donors' organs or cellular blood products/ or endogenous /after reactivation of latent CMV in the post-transplant period/. CMV infections include wide spectrum of clinical signs and symptoms [21]. Most cases are mild, presented just by fever, malaise, leukopenia and thrombocytopenia. Focal infections may occur, commonly involving the parenchyma of transplanted organ: hepatitis in liver transplanted, pancreatitis in pancreas transplanted, pneumonia after heart-lung transplantations, etc $[7,8]$.

- $\boldsymbol{H S V}$ - infection is presented as two clinical forms: primary infection in seronegative recipients or reactivation in previously infected. The symptoms occur in the first month after transplantation and may be presented as herpes labialis, pneumonia /with $75 \%$ risk for death no matter of acyclovir treatment/, tracheobronchitis, esophagitis, hepatitis, skin involvement [22].

- $\boldsymbol{V Z V}$ - primary infection with VZV in seronegative recipient is associated with severe forms of chickenpox, complicated with hemorrhagic pneumonia, encephalitis, hepatitis, pancreatitis, purpura fulminans, while reactivation leads to shingles occurrence in the next 6 months, with dissemination tendency, affecting two or more dermatomes [18].

- $\boldsymbol{E B V}$ - three forms of EBV infections are typical for transplant recipients - fever of unknown origin, mononucleosis or posttransplantation lymphoproliferative disease /PTLP/. Risk factors for EBV infection are seronegative patients or those treated after transplantation by OKT3 monoclonal antibodies or tacrolimus. Highest frequency of EBV infections is seen in small bowels transplantations - 14\%, while EBV is responsible just for $1 \%$ of infections in kidney transplant recipients $[5,16,17]$.

- $\boldsymbol{H B V}$ - causes fulminant hepatitis in $1 \%$ of acutely infected, resulting in life-threating liver failure. Also, an approved association between chronic infection and liver cirrhosis exists. In both cases, liver transplantation is a choice of treatment, but there is $80-90 \%$ possibility for HBV reactivation /the percent is lower in patients with concomitant hepatitis D virus infection/ with 50-60\% mortality rate [6,7]. In contrast, mild form of hepatitis appears when recipient is infected after blood transfusion or transplantation of liver from infected donors. The risk period for clinically presented reactivated HBV is 2-6 month after transplantation, ranging from mild to severe, life-threating hepatitis [12].

- $\boldsymbol{H C V}$ - after primary infection with HCV, symptomatic hepatitis occurs just in $25-30 \%$. In $70-80 \%$ of acutely infected, the disease takes chronic course with liver cirrhosis in the next 20 years, which is seen in $20-30 \%$ of patients, following by hepatic cell carcinoma occurrence in $1-5 \%$ of them. Serotype $1 \mathrm{~b}$ is associated with high morbidity rate and infection in transplanted patients results in high incidence of HCV recurrence [12].

- HIV - transplanted HIV positive recipients needs of lower doses of immunosuppressive drugs and they develop AIDS approximately 17 months later. However, the mean period from 
transplantation to AIDS development after primary infection is 32 months. Soon after transplantation, HIV-infected patients present to the hospital with many complaints such as prolonged fever, liver, spleen and lymph nodes enlargement, malaise, loss of appetite and other non-specific symptoms. The risk for opportunistic infections depends on the CD4 count which is similar to "general" population $[7,17]$.

- Papovaviruses - include two main kinds of viruses, so called $\mathrm{JC}$ and BK virus. They are associated with progressive multifocal leukoencephalopathy /PMLE/ or rejection of transplanted kidney, respectively and both are reported in renal transplant recipients [19].

Various fungi have specific place as causative agents of many infections in transplanted patients. The risk for fungal infection is estimated to be 5 to $17 \%$ in heart, 14 to $22 \%$ in heart-lung, 2 to $42 \%$ of liver, and 2 to $14 \%$ of kidney transplanted recipients. Precipitating factors include using of high dose steroids, previous episode of graft rejection, elderly person, leukopenia or chronic hyperglycemia. Commonly isolated agents are Candida spp., Aspergillus spp., Cryptococcus neoformans, Pneumocystis carinii, Hystoplasma capsulatum, Blastomyces dermatitidis, Paracoccidioides brasiliensis. There are no specific signs in clinical presentation of those infections and symptoms overlap another, common infectious diseases, leading to misdiagnosis and high mortality rate varying between $27-77 \%[11,15,21]$.

Mycobacterium tuberculosis /causing tuberculosis, TBC/ occurs in about $1 \%$ of solid-organ transplant recipients with $30 \%$ mortality rate [14]. The clinical presentation includes fever, but night sweating and weight loss are not common unlike those who are not transplanted. Nontuberculous mycobacteria, such as M. kansasii, M. avium-intracellulare, M. fortuitum, M. xenopi, $M$. haemophilum, M. marinum, M. chelonae, M. abscessus, M. gastri, $M$. scrofulaceum, and M. thermoresistibile often mimic TBC, but when lungs are involved pyrexia is not a common sign. Clinical course includes chronic infections of skin and joints of the digits, wrists, elbows, ankles, and knees. The risk period for these manifestations is 10 days to 269 months after transplantation $[6,7]$.

From the parasitic infections, Toxoplasma gondii and Strongyloides stercoralis are the most important agents because of their distinctive presentation - infections of the central nervous system 7 years after transplantation, or gastrointestinal tract involvement in the first 6 months in the post-transplant period [4].

Different infections occur in specific patterns after transplantation. A strategic approach to fever (and associated organ system-related manifestations) in the solid organ transplantation recipient includes the following steps /see figure1/:

The problem about infections in transplanted patients is actual in nowadays because of increasing frequency of transplantations worldwide. The recipients are specific risk group for various infectious diseases because they may be infected with different agents, leading to atypical clinical presentation. The specific prophylaxis, early diagnosis of the infection and appropriative treatment are the "three mains" for saving patients' life.

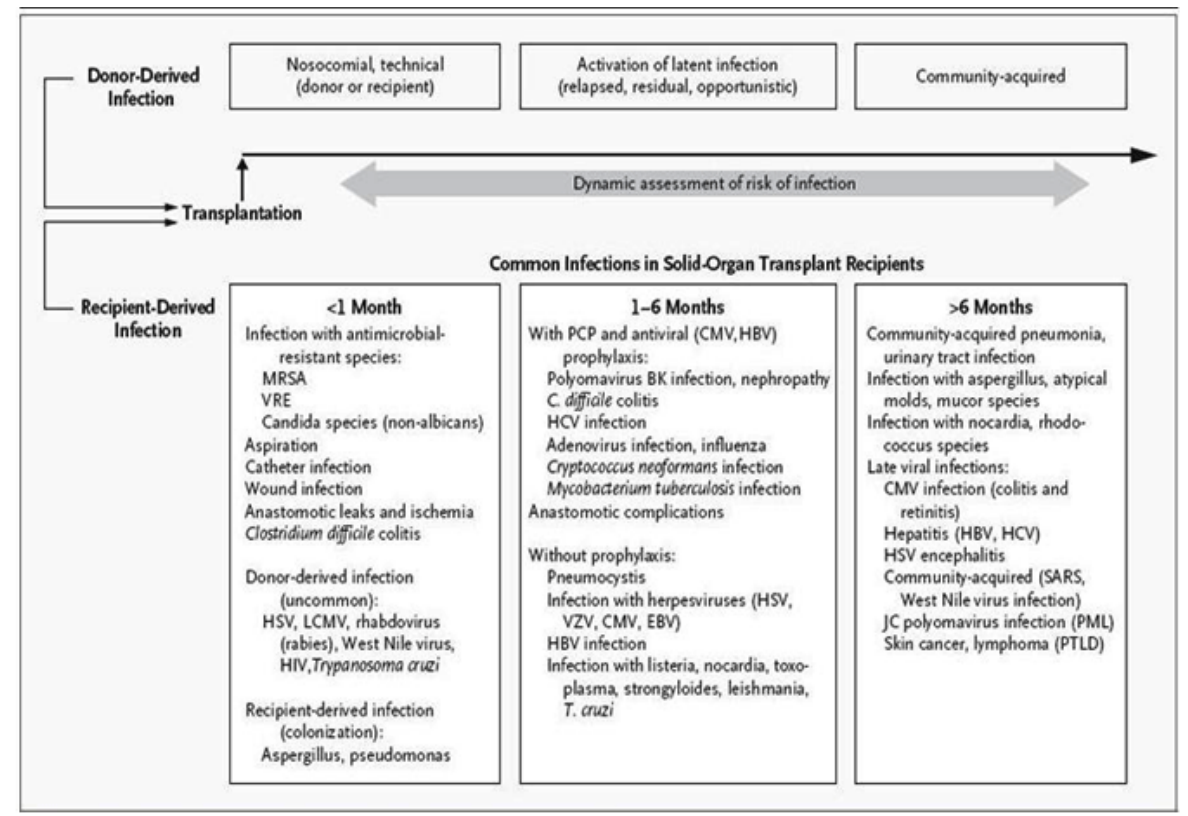

Figure 1: Changing timeline of infection after organ transplantation (modified from Fishman J. NEJM. 2007;357(25):2601-14). 


\section{References}

1. American Journal of Transplantation. Special Issue: The American Society of Transplantation Infectious Diseases Guidelines 3rd Edition. Wiley Online Library. 2014. Available from: http://onlinelibrary.wiley. com/doi/10.1111/ajt.2013.13.issue-s4/issuetoc

2. Bouza E, Loeches B, Munoz P. Fever of unknown origin in solid organ transplant recipients. Infect Dis Clin North Am. 2007;21(4):10331054, ix-x.

3. Clark NM, the AST Infectious Diseases Community of Practice. Nocardia in solid organ transplant recipients. Am J Transplant. 2009;9(S4):S70-S77.

4. Coster LO. Parasitic infections in solid organ transplant recipients. Infect Dis Clin North Am. 2013;27(2):395-427.

5. Fisher RA. Cytomegalovirus infection and disease in the new era of immunosuppression following solid organ transplantation. Transpl Infect Dis. 2009;11(3):195-202. doi: 10.1111/j.13993062.2009.00372.x

6. Fishman JA. Infection in solid-organ transplant recipients. N Engl ] Med. 2007;357(25):2601-2614.

7. Fishman JA, AST Infectious Diseases Community of Practice. Introduction: infection in solid organ transplant recipients. Am J Transplant. 2009;Suppl 4:S3-S6. doi: 10.1111/j.16006143.2009.02887.x

8. Fishman JA, Rubin RH. Infection in organ-transplant recipients. N Engl J Med. 1998;338(24):1741-1751.

9. Grossi PA, Fishman JA; AST Infectious Disease Community of Practice. Donor-derived infections in solid organ transplant recipients. Am J Transplant. 2009;Suppl 4:S19-S26. doi: 10.1111/j.16006143.2009.02889.x

10. Humar A, Fishman JA. Donor-derived infection: old problem, new solutions? Am J Transplant. 2008;8(6):1087-1088. doi: 10.1111/j.1600-6143.2008.02246.x

11. Kubak BM, Huprikar SS; AST Infectious Diseases Community of Practice. Emerging \& rare fungal infections in solid organ transplant recipients. Am J Transplant. 2009;Suppl 4:S208-S26. doi: 10.1111/j.1600-6143.2009.02913.x
12. Levitsky J, Doucette K; AST Infectious Diseases Community of Practice. Viral hepatitis in solid organ transplant recipients. Am J Transplant. 2009;Suppl 4:S116-S30. doi: 10.1111/j.1600-6143.2009.02902.x

13. Munoz P, Palomo J, Guinea J, Yanez J, Giannella M, Bouza E. Relapsing Rhodococcus equi infection in a heart transplant recipient successfully treated with long-term linezolid. Diagn Microbiol Infect Dis. 2008;60(2):197-199.

14. Munoz P, Rodriguez C, Bouza E. Mycobacterium tuberculosis infection in recipients of solid organ transplants. Clin Infect Dis. 2005;40(4):581587.

15. Organ Donation Statistics. organdonor.gov. 2017. Available from: http://www.organdonor.gov/about/data.html?gclid=CKCI27aH8cICF QdsfgoddDoAbQ

16. Patel R, Paya CV. Infections in solid-organ transplant recipients. Clin Microbiol Rev. 1997;10(1):86-124.

17. Peleg AY, Husain S, Kwak EJ, Silveira FP, Ndirangu M, Tran J, et al. Opportunistic infections in 547 organ transplant recipients receiving alemtuzumab, a humanized monoclonal CD-52 antibody. Clin Infect Dis. 2007;44(2):204-212.

18. Pergam SA, Limaye AP; AST Infectious Diseases Community of Practice. Varicella zoster virus (VZV) in solid organ transplant recipients. Am J Transplant. 2009;Suppl 4:S108-S115. doi: 10.1111/j.16006143.2009.02901.x

19. Randhawa P, Vats A, Shapiro R. The pathobiology of polyomavirus infection in man. Adv Exp Med Biol. 2006;577:148-159.

20. Taylor AL, Watson CJ, Bradley JA. Immunosuppressive agents in solid organ transplantation: Mechanisms of action and therapeutic efficacy. Crit Rev Oncol Hematol. 2005;56(1):23-46.

21.WHO-ONT. Global Observatory on Donation and Transplantation. 2016. Available from: http://www.transplant-observatory.org/

22.Zuckerman R, Wald A; AST Infectious Diseases Community of Practice. Herpes simplex virus infections in solid organ transplant recipients. Am J Transplant. 2009;Suppl 4:S104-S107. doi: 10.1111/j.16006143.2009.02900.x 